\title{
An Introduction to Key Event Mapping: A Primer for Nurse Researchers
}

\author{
Lisa Carter-Harris, PhD, RN, ANP-C [Postdoctoral Fellow] \\ Indiana University School of Nursing, 1111 Middle Drive, NU 418, Indianapolis, Indiana 46202, \\ United States of America, (317) 274-7627 office phone, Icharris@iu.edu
}

\begin{abstract}
To fully understand the events leading to a diagnosis, retrospective recall can help nurse researchers reconstruct important health behavior-related events. However, retrospective recall can be a challenge. Key event mapping offers nurse researchers a method beyond retrospective chart review to elicit date data to explore the pre-diagnosis time frame of an illness. The purpose of this paper is to introduce the key event mapping method to nurse researchers in search of a method of eliciting date data from participants when designing research studies that include a retrospective recall component.
\end{abstract}

\section{Keywords}

key event mapping; retrospective recall; calendar land marking technique; method

\section{Introduction}

Retrospective recall to establish time frames or specific dates can be an important component in a research study design. Some research questions can best be addressed retrospectively because they involve asking an individual that has experienced an event or set of events to think back to its initial presentation. Retrospective recall offers the researcher insight into a key time period in an individual's life that can help us better understand the broader context. This is particularly important when trying to understand medical help-seeking behavior for symptoms of concern and has been explored in cancer ${ }^{1-3}$ and acute cardiovascular events. ${ }^{4,5}$

Retrospective recall can add an important dimension to a study's design and provide a venue to explore important research questions and hypotheses, despite known limitations. For example, lung cancer is associated with high mortality rates ${ }^{6}$ and many are thought asymptomatic when diagnosed. ${ }^{7}$ However, many lung cancer patients experience symptoms prior to being diagnosed and understanding this pre-diagnosis time period from the

\footnotetext{
(C) 2015 Published by Elsevier Inc.
}

Publisher's Disclaimer: This is a PDF file of an unedited manuscript that has been accepted for publication. As a service to our customers we are providing this early version of the manuscript. The manuscript will undergo copyediting, typesetting, and review of the resulting proof before it is published in its final citable form. Please note that during the production process errors may be discovered which could affect the content, and all legal disclaimers that apply to the journal pertain. 
individuals' perspective is valuable. Specifically, exploring symptoms suggestive of lung cancer and subsequent medical help-seeking behavior offered the researcher a unique opportunity to examine the temporal trajectory of the pathway to a lung cancer diagnosis.

Explicating and understanding retrospective recall can be a challenge. ${ }^{3}$ Retrospective recall is subject to recall bias or error, which may affect accuracy and completeness of the collected data. Many research studies choose to focus on the reconstruction of life events to understand an event more robustly and completely. ${ }^{8,9}$ Specific to medical help-seeking behavior, many studies use retrospective chart review to establish timeframes. ${ }^{10,11}$ However, this forces the researcher to depend on the accuracy of the recorder. In addition, dates established by chart review do not reflect the critical time to diagnosis period that the researcher is trying to assess. Therefore, studies on medical help-seeking behavior using retrospective chart review miss this critical component and understanding is diminished.

This paper seeks to demonstrate how key event mapping can be used in research studies employing retrospective recall to answer the research question posed more robustly. A central tenet of this work lies in linking the individual experience with key events that are personal and specific to aide with recall. In the author's opinion, key event mapping is an effective method to assist with time-specific date recall and has practical implications for nurse researchers. Therefore, the purpose is to introduce the key event mapping method to nurse researchers in search of a method of eliciting date data from participants. A brief overview is discussed including data source followed by theoretical perspectives and methodological discussion about key event mapping outlining how this method can be employed in data collection procedures of a study.

\section{Background}

Key event mapping is a method that uses a calendar to assist with time-specific date or timeframe recall. The calendar is used to assist an individual to recall a time period based upon personal, local, culturally specific, or widely known relevant events. This method has been referred to as a calendar-land marking technique. ${ }^{12}$ Calendar techniques have been used in sociology and psychology in an attempt to understand behavior. ${ }^{13,14}$ Calendar-land marking techniques have traditionally been used for retrospective research data collection as a means to improve the quality of the data compared to traditional retrospective survey methods. ${ }^{15,16}$ Historically, the method of incorporating a calendar as an instrument for data collection developed from the social sciences where reconstruction of life histories to answer research questions were important. ${ }^{17,18}$ Reconstructing life histories using a calendar-land marking technique offered the advantage of improving the quality of the retrospective data as well as offering a mechanism to record detailed event sequences compared to conventional survey methods. ${ }^{17}$ Methodologically, calendar techniques have been incorporated into personal interviews ${ }^{19}$, paper-and-pencil questionnaires ${ }^{20}$, and telephone-based interviews ${ }^{21}$ with success. Many studies conducted in the domain of nursing seek to understand health behaviors, and key event mapping is a technique that can be used to retrospectively reconstruct important health behavior-related events. In a recent study, key event mapping was used to explore medical help-seeking behaviors in individuals with symptoms suggestive of lung cancer. ${ }^{3}$ Specifically, the researcher was interested in a 
more robust understanding of the pre-diagnosis timeframe of lung cancer patients. The approach was adapted from the work of Molassiotis and colleagues in which they mapped patient experiences from an initial change in health to an eventual cancer diagnosis. ${ }^{9}$ When employed in a study, key event mapping can be used with every participant interview or as needed if difficulties arise. The 'key events' are used as temporal anchors to recall important time periods (either specific or general frames of time) in relation to the health behavior under study.

\section{Data Source}

This method, key event mapping, was refined in a study entitled 'Influential Variables in the Timing of Help-Seeking Behaviors (HSB) in Lung Cancer Patients' (hereafter referred to as the Lung Cancer HSB study). The overall aim of the Lung Cancer HSB study was to examine the influence of lung cancer stigma, healthcare system distrust, and smoking status on the timing of medical help-seeking behavior in individuals with symptoms suggestive of lung cancer. The researcher was interested in the pre-diagnosis timeframe between symptom awareness and initial medical help-seeking behavior. The study involved 94 individuals diagnosed with non-small cell lung cancer of all four stages. Participants were recruited to examine levels of lung cancer stigma and healthcare system distrust using established valid and reliable Likert-style scales. ${ }^{22,23}$ The researcher also explored their medical help-seeking behavior in the context of their lung cancer diagnosis using a semi-structured interview format. Key event mapping was used to assist with timeframe recall and will be discussed first in the context of theory and then detailed in method.

\section{Theoretical Perspectives}

Key events in the pre-diagnosis trajectory of a disease can be viewed as a series of transitions culminating in a defining event of transition from pre-diagnosis to post-diagnosis. Every experience is different and individually defined but there are elements of similarity along the pathway to a diagnosis. These may include the transition from feeling 'normal', 'healthy', or 'well' to feeling 'bad', 'under the weather', or 'ill'. Another transition may be conceptualized as believing the situation is acute and transitioning to the realization of its chronicity.

Transition is a key variable in medical help-seeking behavior and can be operationalized as either an independent or dependent variable. As an independent variable, the transition process can be viewed as a course of change involving health, medical help-seeking, or health care utilization. As a dependent variable, the transition process itself as well as the perceived change in health can be operationalized. In the context of a lung cancer diagnosis, key event mapping is valuable in documenting the pathway because the process of key event mapping helps define the course more completely from the perspective of the individual. Specifically, the pathway itself toward a lung cancer diagnosis can be viewed as a process of transition. Therefore, the elements of the process, timespan, and perception of events are documented through recall using key event mapping to reconstruct a timeline that can assist the researcher in analyzing both the patterns of response to the transition events and its associated dimensions. ${ }^{24}$ 


\section{Method}

The following will present specific steps to take in key event mapping. It is optimal to begin an interview that plans to assess events using retrospective recall by explaining that if the participant has difficulty with recall, a method called key event mapping can be used. It is helpful to explain that the researcher will use a calendar to prompt the participant to think back to key events that may provide context for the health behavior being discussed. To employ key event mapping, it is beneficial to use a large calendar that displays all months of one calendar year on one large page. It is also useful to provide colorful sketches or figures on internationally known holidays (i.e. Christmas, Easter, New Year's Eve or Day) and nationally known events that are specific to the region in which the research is being conducted. This will visually reinforce the key event (in this case, holiday) quickly as the participant visualizes the calendar. Next, ask the participant to recall the event in relationship to the season specific to normal weather trends in the area. Probing questions can be helpful in mentally transporting the participant to the event the researcher is trying to elicit in recall. For example: Was it warm or cold outside? Do you remember if leaves were on the ground or was it snowing? Mentally walking the individual through the season can help them contextualize the desired event of recall. After establishing the season with the participant, the researcher can focus on key events in the months that comprise the season. For example, if the study is being conducted in the United States and the participant recalls their cough began in the fall when leaves were on the ground, asking a question such as: $d o$ you recall if you had the cough before Thanksgiving? may help the individual to continue refining their timeline. This method can easily be adapted to cultural specific events of the geographic location of the study. In addition, depending upon your purpose, the timeframe may be more important than the specific date. For example, in the recent Lung Cancer HSB study, the researcher was interested in the time from symptom onset to medical help-seeking behavior. The researcher operationalized medical help-seeking behavior as the first phone call to the healthcare provider's office for an appointment to be evaluated for the symptoms of concern. In this example, key event mapping was helpful in eliciting participant recall about how much time had passed between the two events as opposed to the specific date on the calendar. Helpful hints to tackle potential complications using key event mapping can be found in Table 1.

\section{Limitations}

While this paper illustrates practical application of key event mapping, it is important to note that there are limitations to the approach, as with other retrospective recall methods. Key event mapping can be time intensive depending upon the individual encounter. It must be employed in a committed, methodical fashion in order to allow for adequate recall of the data sought for study and to ensure a rigorous process. Calendar techniques have been criticized for their inherent recall bias. ${ }^{25}$ However, choosing not to examine research questions that necessitate retrospective recall leaves an important void in our understanding of key timeframes such as the pre-diagnosis pathway of a diagnosis. Key event mapping, although not a perfect technique, is identified throughout this paper as a viable approach to explore important timeframes that can inform other meaningful research questions and hypotheses. 


\section{Implications for Nursing}

Nurse researchers are increasingly trying to understand important disease processes by contextualizing them within their pre-diagnosis timeframe. As an approach initially popularized by sociological and psychological research, calendar techniques to elicit recall are essential to the questions posed by nurse researchers. Key event mapping is a calendar land marking technique with practical applicability in nursing research and will add rigor to the process. The calendar technique described here was developed to address practical challenges of recall elicitation.

\section{Conclusions}

Some research questions cannot be addressed prospectively and necessitate a retrospective recall component. Because retrospective recall is inherently biased, methods to increase the rigor with which to extract the data are valuable. Key event mapping is one technique to establish time frames and offer insight into key time periods in an individual's life for the purpose of understanding the broader picture.

\section{Acknowledgements}

This research was supported by Grant Number 5 T32 NR007066 from the National Institute of Nursing Research.

\section{References}

1. O'Mahony M, Hegarty J, McCarthy G. Women's help seeking behaviour for self discovered breast cancer symptoms. European Journal of Oncology Nursing: The Official Journal of European Oncology Nursing Society. 2011; 15(5):410-418. [PubMed: 21094088]

2. Lam WW, Tsuchiya M, Chan M, Chan SW, Or A, Fielding R. Help-seeking patterns in Chinese women with symptoms of breast disease: a qualitative study. Journal of Public Health. 2009; 31(1): 59-68. [PubMed: 18948434]

3. Carter-Harris L, Hermann CP, Schreiber J, Weaver MT, Rawl SM. Lung cancer stigma predicts medical help-seeking behavior in adults with lung cancer. Oncology Nursing Forum. 2014; 41(3):E203-E210. [PubMed: 24769603]

4. Higginson R. Women's Help-Seeking Behavior at the Onset of Myocardial Infarction. British Journal of Nursing. 2008; 17(1):10-14. [PubMed: 18399391]

5. O'Donnell S, Moser DK. Slow-onset myocardial infarction and its influence on help-seeking behaviors. The Journal of Cardiovascular Nursing. 2012; 27(4):334-344. [PubMed: 21760520]

6. Jemal A, Bray F, Center MM, Ferlay J, Ward E, Forman D. Global cancer statistics. CA: A Cancer Journal for Clinicians. 2011; 61(2):69-90. [PubMed: 21296855]

7. Corner J, Hopkinson J, Fitzsimmons D, Barclay S, Muers M. Is late diagnosis of lung cancer inevitable? Interview study of patients' recollections of symptoms before diagnosis. Thorax. 2005; 60(4):314-319. [PubMed: 15790987]

8. Brindle L, Pope C, Corner J, Leydon G, Banerjee A. Eliciting symptoms interpreted as normal by patients with early-stage lung cancer: could GP elicitation of normalised symptoms reduce delay in diagnosis? Cross-sectional interview study. BMJ Open. 2012; 2(6)

9. Molassiotis A, Wilson B, Brunton L, Chandler C. Mapping patients' experiences from initial change in health to cancer diagnosis: a qualitative exploration of patient and system factors mediating this process. European Journal of Cancer Care. 2010; 19(1):98-109. [PubMed: 19552730]

10. Braquehais M, Valero S, Matali JL, Bel MJ, Montejo JE, Nasillo V, Arteman A, Padros J, Bruguera E, Casas M. Promoting voluntary help-seeking among doctors with mental disorders. 
International Journal of Occupational Medicine \& Environmental Health. 2014; 27(3):435-443. [PubMed: 24952142]

11. Brocken P, Kiers BA, Looijen-Salamon MG, et al. Timeliness of lung cancer diagnosis and treatment in a rapid outpatient diagnostic program with combined 18FDG-PET and contrast enhanced CT scanning. Lung Cancer. 2012; 75(3):336-341. [PubMed: 21943652]

12. Emery J, Walter FM, Gray V, Sinclair C, Howting D, Bulsara M, Bulsara C, Webster A, Auret K, Saunders C, Nowak A, Holman CD. Diagnosing cancer in the bush: A mixed-methods study of symptom appraisal and help-seeking behaviour in people with cancer from rural Western Australia. Family Practice. 2013; 30:294-301. [PubMed: 23363540]

13. Giele, JE. Methods of life course research: Qualitative and quantitative approaches. Thousand Oaks, CA: SAGE Publications; 1998.

14. Turner R, Wheaton B, Lloyd DA. The epidemiology of social stress. American Sociological Review. 1992; 60(1):104-125.

15. Belli R, Lee EH, Stafford F, Chou CH. Calendar and question-list survey methods: Association between interviewer behaviors and data quality. Journal of Official Statistics. 2004; 20(1):185218.

16. Martyn K, Belli RF. Retrospective data collection using event history calendars. Nursing Research. 2002; 51(4):270-274. [PubMed: 12131240]

17. Freedman D, Thornton A, Camburn D, Alwin D, Young-DeMarcco L. The life history calendar: A technique for collecting retrospective data. Sociological Methodology. 1988; 18:37-68. [PubMed: 12282712]

18. Sobell L, Sobell MB, Leo GI, Cancilla A. Reliability of a timeline method: Assessing normal drinkers' reports of recent drinking and a comparative evaluation across several populations. British Journal of Addiction. 1988; 83:393-402. [PubMed: 3395719]

19. Van der Vaart W. The time-line as a device to enhance recall in standardized research interviews: A split ballot study. Journal of Official Statistics. 2004; 20(2):301.

20. Martyn K, Martin R. Adolescent sexual risk assessment. Journal of Midwifery and Women's Health. 2003; 48(3):213-219.

21. Van Der Vaart W, Glasner T. Applying a timeline as a recall aid in a telephone survey: A record check study. Applied Cognitive Psychology. 2007; 21(2):227-238.

22. Cataldo J, Slaughter R, Jahan TM, Pongquan VL, Hwang WJ. Measuring stigma in people with lung cancer: Psychometric testing of the cataldo lung cancer stigma scale. Oncology Nursing Forum. 2011; 38(1):E46-E54. [PubMed: 21186151]

23. Shea J, Micco E, Dean LT, McMurphy S, Schwartz JS, Armstrong K. Development of the revised Health Care System Distrust scale. Journal of General Internal Medicine. 2008; 23:727-732. [PubMed: 18369678]

24. Meleis, A. Transitions theory: Middle-range and situation-specific theories in nursing research and practice. New York, NY: Springer Publishing Company; 2010.

25. Belli R, Bilgen I, Baghal TA. Memory, communication, and data quality in calendar interviews. Public Opinion Quarterly. 2013; 77(S1):194-219. 


\section{Table 1}

\section{Helpful hints to tackle potential complications in key event mapping}

- Use a dry erase board in tandem to help visually construct the timeline as the participant recalls key events.

- Before beginning, have participant identify some important personal dates and add those to the calendar (i.e. the participant's birthday, birth of a grandchild, son's college graduation, wedding anniversary).

- Have the participant share the date they were diagnosed with the disease the researcher is exploring. Many individuals are keenly aware of a 'date of diagnosis' and this can be used as a visual reference on the calendar for the key event mapping process.

- Refrain from using a calendar that lists one month per page. Turning pages and not being able to visualize an entire year is counterproductive in key event mapping. 